\title{
$\mathrm{Co}_{65} \mathrm{Al}_{35}$ 金属粉机械合金化致非晶研究*
}

\author{
孙道智 程力智 张玉梅 董心权 熊湘源 何开元
}

(东北工学院材料科学与工程系, 沈阳 113006)

\section{关调 $\mathrm{Co}-\mathrm{Al}$ 合金、机械合金化、非晶化}

\section{一、引 声}

机械合金化形成非晶是近年来非晶态物理与材料研究中既有理论意义又具实用价值的课 题出. 通常认为,体系有大而负的混合热是机械合金化非晶形成的必要热力学条件, 足够小的 原子尺寸比则是快速原子扩散固态反应所必须. $\mathrm{Co}-\mathrm{Al}$ 系几乎都能满足这样二个条件: 按 文献 [2], $\mathrm{Co}-\mathrm{Al}$ 系非晶形成的热力学参数 $\xi_{\mathrm{Co}-\mathrm{Al}}-6.1$ 与 $\mathrm{Fe}-\mathrm{Zr}\left(\xi_{\mathrm{Po}-\mathrm{Zr}}-6.15\right)$ 相近; 按 文献 [3] 计算的原子体积比为 0.61 , 比 $\mathrm{Ti}-\mathrm{Cu}$ 系的原子体积比(0.68)还小些. 而 $\mathrm{Fe}-\mathrm{Zr} 、 \mathrm{Ti}-$ $\mathrm{Cu}$ 系均为机械合金化非晶形成体系,据此推断 Co-Al 也存在固态反应非晶化的可能性. 为 此, 我们开展了 Co-Al 系机械合金化非晶形成过程的研究.

\section{二、实验方法}

金属 $\mathrm{Al}$ 粉(纯度 $99 \%, 100-200$ 目)和 $\mathrm{Co}$ 粉(纯度 $99 \%, 200$ 目)按 $\mathrm{Co}_{65} \mathrm{Al}_{35}$ 成分配比, 在玛瑙研针中混合后与碳化锁硬质合金球一起放人不锈钢球磨罐中, 球料比 $20: 1$, 加盖抽空 充氮后用自制高能振摆式球磨机进行球磨. 从球磨开始后的 $5 、 10 、 20 、 30 、 40,50 、 60 、 70 \mathrm{~h}$ 分别 停机取样,做 X 射线衍射和 DSC 分析. 前者是在日本理学公司 D/MAX-RB 衍射仪上做的, 后者则在上海天平仪器厂 $\mathrm{CDR}-1$ 型差动热分析仪上进行.

\section{三、实 验 结果}

$\mathrm{C}_{63} \mathrm{Al}_{35}$ 金属粉经不同时间球磨后的 $\mathrm{X}$ 射线行射谱如图 1 所示. 由图可见, 在球磨初期 （球磨 5h 以前）体系由 CoAl 化合物及纯 Co 所组成; CoAl 化合物主峰位置与 ASTM 标准 卡相周. 随着球磨时间的增长, 化合物及纯 Co 衍射峰强度逐渐降低, 30h 后纯 Co 峰完全消 失. 进一步球磨 (30-70h) 化合物衍射峰展宽直至呈现非晶相所特有的漫散射谱.

图 2 为经 $70 \mathrm{~h}$ 球磨以及 $400^{\circ} \mathrm{C}$ 退火的 $\mathrm{CO}_{65} \mathrm{Al}_{35}$ 粉的 DSC 热谱. 其 中 a 是球磨粉的 DSC 迹线,它包含二个放热峰: 一个是 $270^{\circ} \mathrm{C}$ 附近的低温放热峰, 另一个是 $425^{\circ} \mathrm{C}$ 附近出现 的高温放热峰. 为检验低温放热峰是否是非晶晶化峰,对球磨粉在 $3400^{\circ} \mathrm{C}$ 氢气保护下退火 10 $\min$ 后再做 $X$ 射线分析发现体系并未晶化,继续对样品做 $540^{\circ} \mathrm{C}$ 氢气保护退火 $10 \mathrm{~min}$, 再做 $\mathrm{X}$ 射线分析才见到明显的晶化衍射峰,因此低温峰并非晶化峰, 高温峰才对应于体系的晶化过 程.

本文 1990 年9月13 日收到. 1991 年 6 月11 日收到隹改稿.

- 圈家自然科学基金资助项目. 


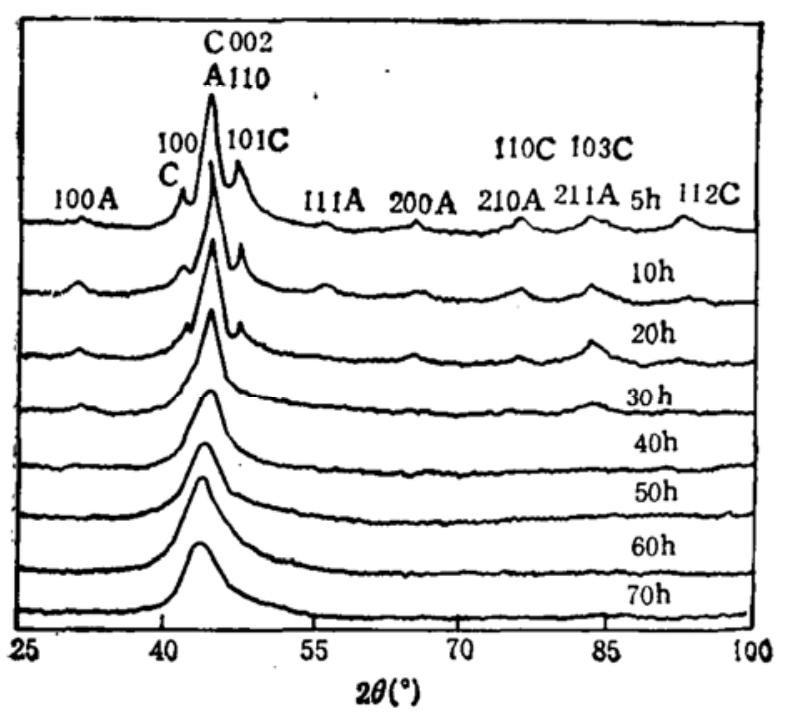

图 1 经不同时间球察 $\mathrm{Co}_{6}, \mathrm{Al}_{3}$, 粉的 $\mathbf{X}$ 射线衍射谱

$A$ 为 CoAl 化合物; C 为六方晶形 Co

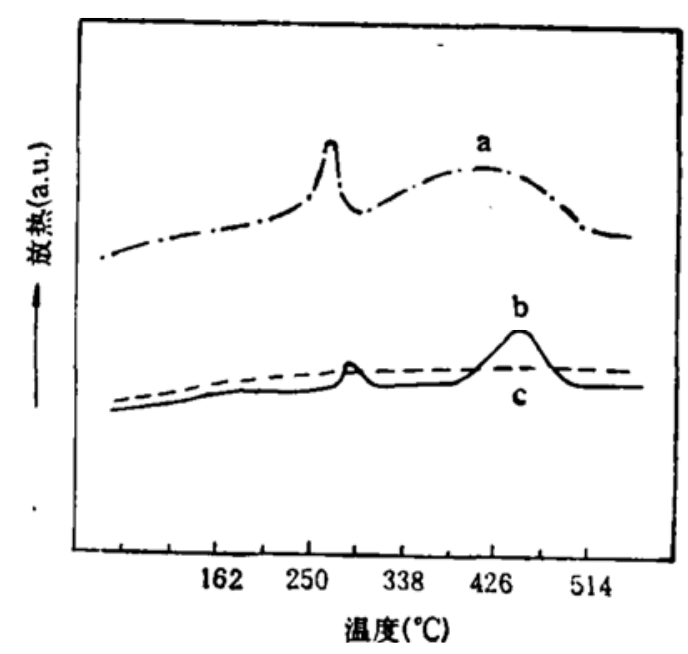

图 2 经 $70 \mathrm{~h}$ 球庭以及 $400^{\circ} \mathrm{C}$ 退火的 $\mathrm{Co}_{6}, \mathrm{Al}_{3}$, 粉 DSC 热谱

2. 球磨粉; b. 球磨粉经 $400{ }^{\circ} \mathrm{C}, 10 \mathrm{~min}$ 基空退火; c. 经处理(与b同) DSC 扫描后, 再做 DSC 扫描

鉴于球磨 $\mathrm{Co}_{65} \mathrm{Al}_{35}$ 粉的 DSC 迹线(图 2a 线)与常见的机械合金化致非晶体系(晶化过程 对应的是高温下锐利的放热峰, 非晶形成或完善化 对应的是低温下较宽平的放热峰)有明显差异,我们 对该球磨粉进行了不同寻常的处理: 将 $70 \mathrm{~h}$ 球磨粉 $400{ }^{\circ} \mathrm{C}$ (大约是在图 2 中 a 线所示高温晶化放热峰 前 $20^{\circ} \mathrm{C}$ )于真空中退火 $10 \mathrm{~min}$ 后再取样做 DSC 扫 描, 结果如图 2 中 $\mathrm{b}$ 线所示. 可见球磨粉在退火后 其 DSC 热谱包含有清晰可辨的高、低二个放热峰. 为进一步了解这二个放热峰的性质, 将上述经退火 处理后的球磨粉分别取样再在 $320^{\circ} \mathrm{C} 、 500^{\circ} \mathrm{C}$ 下退火 $5 \mathrm{~min}$. 图 3 给出了它们的 X 射线衍射谱, 对比后可 见, 图 2 中的低温峰是非晶完善峰(其性质还有待进 一步深入研究), 高温峰乃非晶晶化峰. 图 2 中 $\mathrm{c}$ 线 是经 $\mathrm{b}$ 线所示 DSC 扫描后再次由室温做 DSC 扫 描所得迹线, 可见 $\mathrm{b}$ 线中二个放热峰对应的是从亚 稳向稳态的转变.

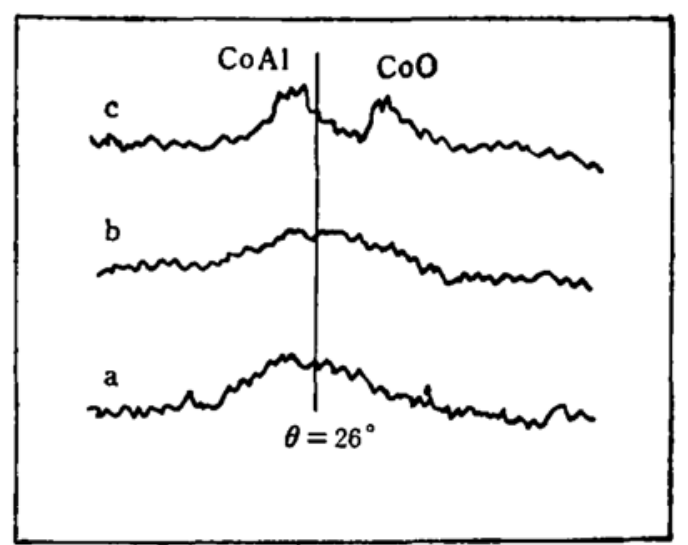

图 3 退火球㿑粉再经低、高温退火后的 $\mathbf{x}$ 射线衍射谱

a. 经 $4000^{\circ} \mathrm{C}, 10 \mathrm{~min}$ 退火球窟粉; b. 再经 $320 \mathrm{t}$, $5 \mathrm{~min}$ 退火; c. 再经 $5000^{\circ}$, 5 min 退火

本工作还按 Kissinger 峰移法对图 2 中迹线 $\mathrm{b}$ 作了动力学分析,经分析后知高、低放热峰 所对应的过程激活能分别为 $116 \mathrm{~kJ} \cdot \mathrm{mol}^{-1} 、 120 \mathrm{~kJ} \cdot \mathrm{mol}^{-1}$. 可见该数值比通常固态反应非晶 化体系的相应值为低. 经 $70 \mathrm{~h}$ 球磨并在 $400{ }^{\circ} \mathrm{C}$ 下 $10 \mathrm{~min}$ 真空退火的 $\mathrm{Co}_{65} \mathrm{Al}_{35}$ 粉中非晶相的 晶化激活能 $\left(116 \mathrm{~kJ} \cdot \mathrm{mol}^{-1}\right)$ 大约只有 $\mathrm{Ni}-\mathrm{Zr}$ 系晶化激活能 ${ }^{[4.5]}$ 的一半.

\section{四、结论}

1. $\mathrm{Co}_{65} \mathrm{Al}_{35}$ 金属混合粉经长时间 (70h) 球磨机械合金化可形成非晶, 过程是: 纯金居 
混合粉 $\rightarrow$ (CoAl 化合物十纯 Co 晶相)混合物 $\rightarrow$ 纯 Co 溶入化合物形成亚稳(非晶)相.

2. $\mathrm{Co}_{65} \mathrm{Al}_{35}$ 球磨粉只是在晶化温度前某温度下退火后, 其 DSC 迹线才出现明显的晶化 放热就,其相应的晶化激活能大约只有 $\mathrm{Ni}-\mathrm{Zr}$ 系的一半.

\section{考文都}

[1] Schultx, L., Materials Science and Engineering, 97(1988), 15-23.

[2] 孙进第等,六届全国相图会议文集, 沈阳, 1990,61-65.

[3] Miedema, A. R., Niessen, A.K., Physica B, 114(1983), 367-374.

[4] Battezzati, L. et al., J. Less-Common Metals, 145(1988), 301-308.

[5] Weeber, A. W., Bakker, H., Physica B, 153(1988), 93-135. 